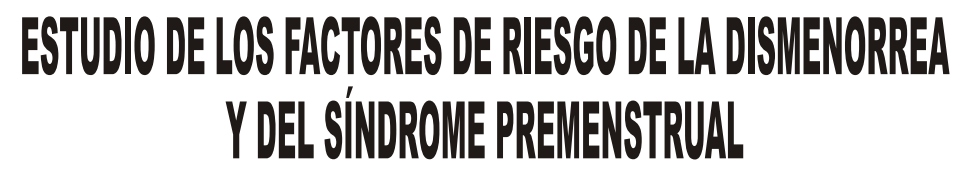

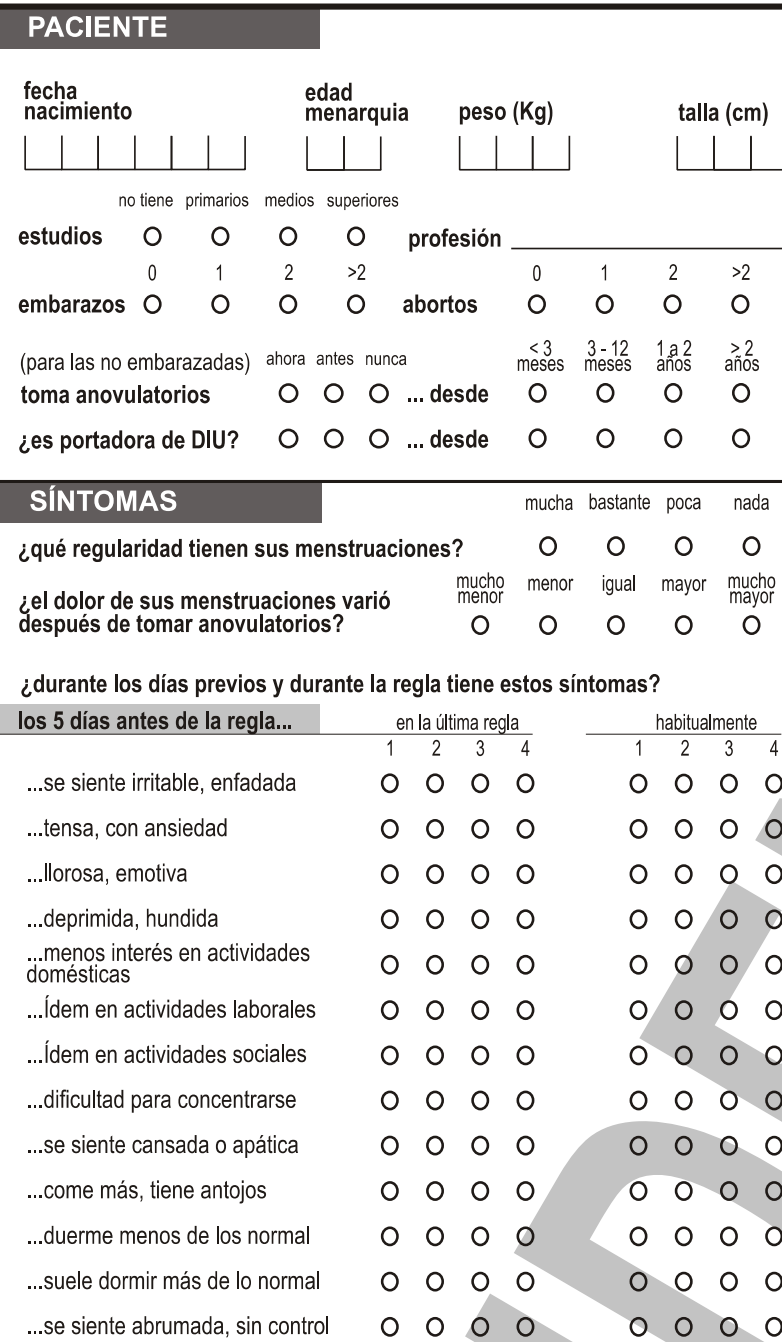

¿tuvo 1 ó más de los siguientes síntomas: pechos sensibles, dolor de cabeza o $\begin{array}{lllllllll}\begin{array}{l}\text { muscular, vientre hinchado } 0 \\ \text { sintió como si ganara peso? }\end{array} & 0 & 0 & 0 & 0 & 0 & 0 & 0 & 0\end{array}$

¿algún problema anterior interfirió en su rendimiento laboral?

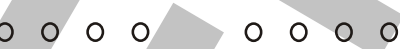
...en su relación con sus compañeros? $\quad 0 \quad 0 \quad 0 \quad 0$ ...en su relación con sus familiares? $0 \quad 0 \quad 0 \quad 0$ ...en su vida social? $\begin{array}{lllllllllll}0 & 0 & 0 & 0\end{array}$ $\begin{array}{lllllll}0 & 0 & 0 & 0\end{array}$ ...en las tareas de su hogar? $\begin{array}{lllllllllllll}0 & 0 & 0 & 0\end{array}$ $\begin{array}{lllll}0 & 0 & 0 & 0\end{array}$

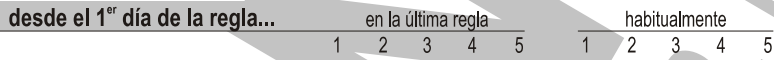
...tiene retortijones abdominales $\quad 0 \begin{array}{llllllllll}0 & 0 & 0 & 0 & 0 & 0 & 0 & 0 & 0\end{array}$ $\begin{array}{lllllllllll}\text {...tiene dolor intermitente } & 0 & 0 & 0 & 0 & 0 & 0 & 0 & 0 & 0 & 0\end{array}$ $\begin{array}{llllllllllllllll}\text { c... } & \text { ce acurruca en cama con algo } & 0 & 0 & 0 & 0 & 0 & 0 & 0 & 0 & 0 & 0\end{array}$

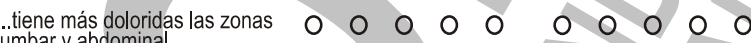
lumbar y abdominal

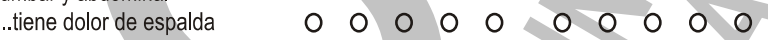
...tiene náuseas $\begin{array}{lllllllllll}0 & 0 & 0 & 0 & 0 & 0 & 0 & 0 & 0 & 0\end{array}$ durante la regla... en la última regla habitualmente $\begin{array}{lllllllllll}1 & 2 & 3 & 4 & 5 & 1 & 2 & 3 & 4 & 5\end{array}$

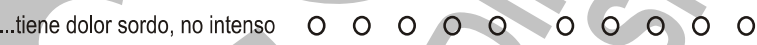
...toma aspirina para el dolor 00000000000000 ...toma otro medicamento $\begin{array}{llllllllllllllllllllllll}0 & 0 & 0 & 0 & 0 & 0 & 0 & 0 & 0 & 0\end{array}$ ...se siente débil o mareada $\begin{array}{lllllllllllllllllllllll}0 & 0 & 0 & 0 & 0 & 0 & 0 & 0 & 0 & 0\end{array}$ ...tiene diarrea $\begin{array}{lllllllllllllllllllllll}0 & 0 & 0 & 0 & 0 & 0 & 0 & 0 & 0 & 0\end{array}$ ...tiene estreñimiento

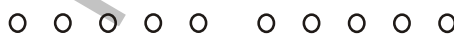

...el dolor dura (días)... en la última regla

habitualmente , $\begin{array}{llllllllllll}\text {...el dolor le incapacita en su } & 0 & 0 & 0 & 0 & 0 & 0 & 0 & 0 & 0 & 0\end{array}$ $\begin{array}{lllllllll} & < & 1 & 2 & >2 & \text { no } & < & 1 & 2\end{array}$ $0 \begin{array}{llllllllll}0 & 0 & 0 & 0 & 0 & 0 & 0 & 0 & 0 & 0\end{array}$ ¿el dolor interfirió en su $\quad$ nada algo bastante mucho nada algo bastante mucho

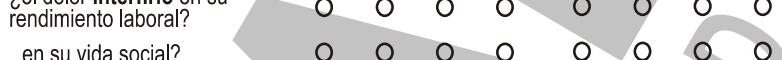
$\begin{array}{lllllllll}\text {...en su vida social? } & 0 & 0 & 0 & 0 & 0 & 0 & 0 & 0\end{array}$ $\begin{array}{lllllllll}\text {...en las tareas del hogar? } & 0 & 0 & 0 & 0 & 0 & 0 & 0 & 0\end{array}$ ...la hemorragia es... escasa moderada abundante escasa moderada abundante COMORBILIDADES ¿ha sido diagnosticada de alguna de las siguientes $0 \quad 0 \quad 0 \quad 0<0$ enfermedades? Si fue así ¿a qué edad comenzó? (puede cubrir más de una opción) diagnosis
médica sin HC medica en HC

ovario poliquístico

endometriosis

0

MEDICAMENTOS

0

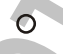

O 3 veces por semana algún medicamento? (incluidos complejos vitamínicos)

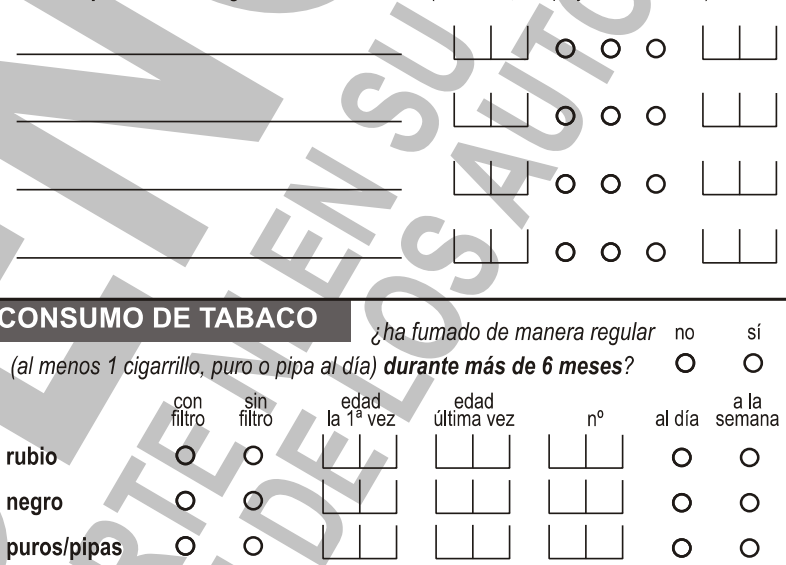

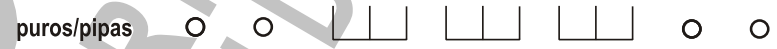

$\begin{array}{lllllll}\mathrm{n}^{\circ} \text { personas que fuman en casa } & 0 & 1 & 2 & 3 & 4 & >4 \\ & 0 & 0 & 0 & 0 & 0 & 0\end{array}$

$\begin{array}{lllllll}\text { icuántas horas pasa a la semana en } & <1 & 10 ́ 2 & 30 ́ 4 & 50 ́ 6 & 7 \mathrm{u} 8 & >8\end{array}$

$\begin{array}{lllllll}\text { ¿uantares en los que la gente fuma? } & 0 & 0 & 0 & 0 & 0 & 0\end{array}$

\section{EJERCICIO FÍsICO}

su actividad física comparando con otras personas de su misma edad es..

¿cuántos minutos dedica al día a caminar o ir en bicicleta al trabajo o de compras?

en su tiempo libre...

... pasea en bicicleta
... practica un deporte
... ve la televisión
... pasea caminando

mucho menor igual mayor mucho
menor

○ 00000

$<5 \quad 6-15 \quad 16-30 \quad 31-45 \quad>45$

○ 00000

nunca raras a a a muy a

O 0 O 00

$\begin{array}{lllll}0 & 0 & 0 & 0 & 0\end{array}$

O 0 O 00

suele hacer algo que le haga sudar

00000

O 0 O 00

si suele practicar algunos deportes o ir al gimnasio, indique la intensidad que requieren y el tiempo que les dedica:

intensidad $\left(1^{\text {er }}\right.$ deporte $)$

$\begin{array}{ccc}\text { pequeña } & \text { media } & \text { grande } \\ 0 & 0 & 0 \\ 0 & 0 & 0\end{array}$

intensidad $\left(2^{\circ}\right.$ deporte $)$

O

O

pequeña: andar; media:

$n^{0}$ horas semanales que dedica a $\quad 1^{\text {er }}$ deporte $\bigsqcup \quad \downarrow$...a $2^{\circ}$ deporte

$n^{0}$ meses al año que dedica a $\quad 1^{\text {er }}$ deporte $\bigsqcup \bigsqcup \quad$...a $2^{\circ}$ deporte 


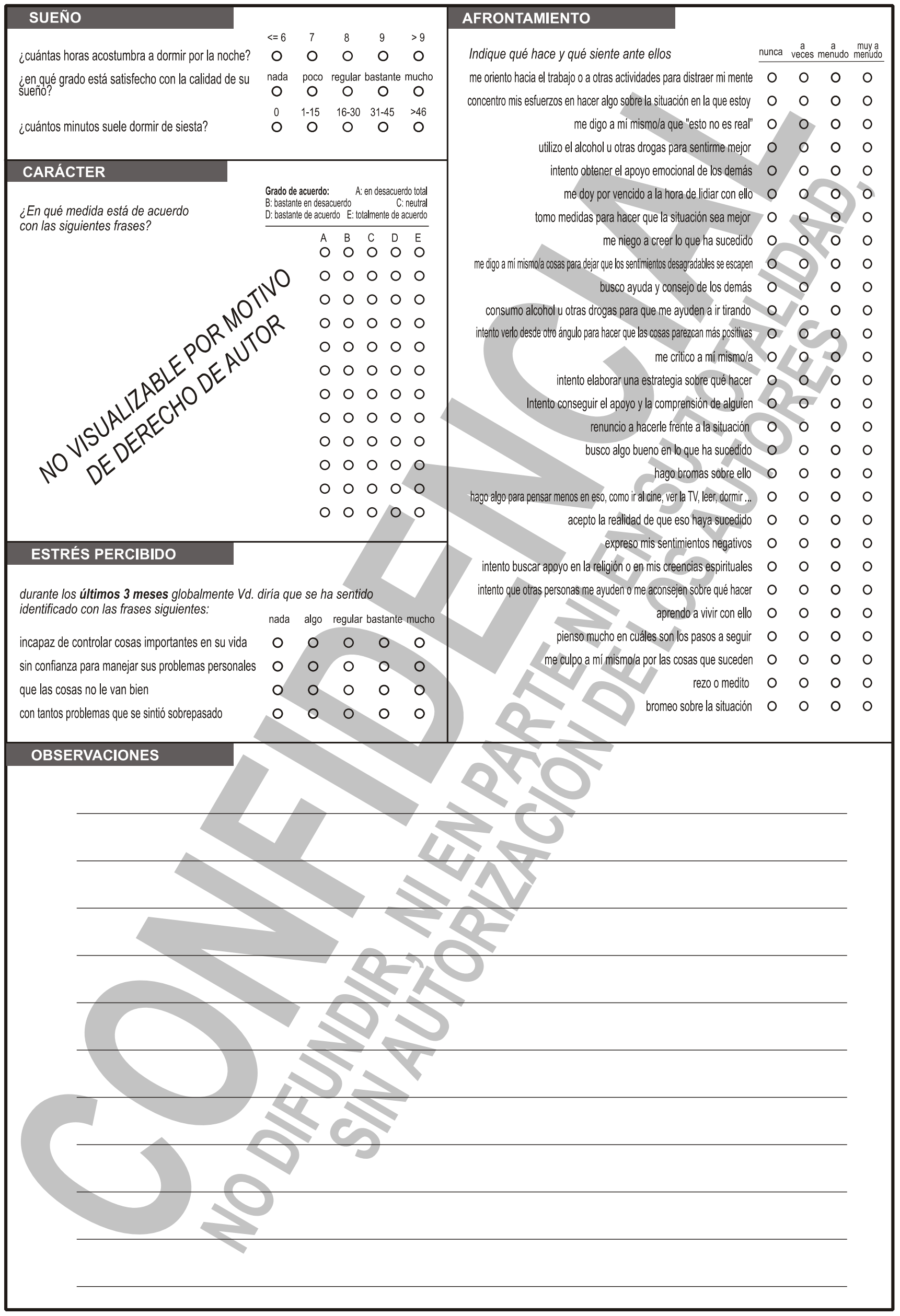

